\title{
Norm-based comparison of the quality-of-life impact of ravulizumab and eculizumab in paroxysmal nocturnal hemoglobinuria
}

\author{
Carolyn E. Schwartz ${ }^{1,2^{*}}$, Roland B. Stark ${ }^{1}$, Katrina Borowiec ${ }^{1,3}$, Sandra Nolte ${ }^{4}$ and Karl-Johan Myren ${ }^{5}$
}

\begin{abstract}
Aims: Paroxysmal nocturnal hemoglobinuria (PNH) is a rare and life-threatening intravascular hematologic disorder with significant morbidity and premature mortality. Clinical trials (NCT02946463 and NCT03056040) comparing ravulizumab with eculizumab for PNH have supported the non-inferiority of the former and similar safety and tolerability. This secondary analysis compared PNH trial participants after 26 weeks on either treatment $(n=438)$ to a generalpopulation sample (GenPop) $(n=15,386)$ and investigated response-shift effects.

Methods: Multivariate analysis of covariance (MANCOVA) investigated function and symptom scores on the European Organisation for Research and Treatment of Cancer (EORTC) QLQ-C30 of people with PNH as compared to GenPop, after covariate adjustment. Risk-factor groups were created based on clinical indicators known to be associated with worse PNH outcomes, and separate MANCOVAs were computed for lower- and higher-risk-factor groups. Differential item functioning (DIF) analyses examined whether item response varied systematically (1) by treatment, (2) compared to GenPop, and (3) over time, the latter two suggesting and reflecting response-shift effects, respectively. DIF analyses examined 24 items from scales with at least two items. Recalibration response shift was operationalized as uniform DIF over time, reflecting the idea that, for a given group, the difficulty of endorsing an item changes over time, after adjusting for the total subscale score. Reprioritization response shift was operationalized as non-uniform DIF over time, i.e., the relative difficulty of endorsing an item over time changes across the total domain score.

Results: Across PNH risk-factor levels, people who had been on either treatment for 26 weeks reported better-thanexpected functioning and lower symptom burden compared to GenPop. Ravulizumab generally showed larger effect sizes. Results were similar for lower and higher PNH risk factors, with slightly stronger effects in the former. DIF analyses revealed no treatment DIF, but did uncover group DIF (9 items with uniform DIF, and 11 with non-uniform) and DIF over time (7 items with uniform DIF, and 3 with non-uniform).

Conclusions: This study revealed that people with PNH on ravulizumab or eculizumab for 26 weeks reported QOL levels better than those of the general population. Significant effects of DIF by group and DIF over time support recalibration and reprioritization response-shift effects. These findings suggest that the treatments enabled adaptive changes.
\end{abstract}

\footnotetext{
*Correspondence: carolyn.schwartz@deltaquest.org

1 DeltaQuest Foundation, Inc., 31 Mitchell Road, Concord, MA 01742, USA

Full list of author information is available at the end of the article
}

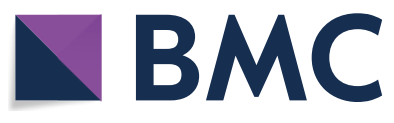

2021. Open Access This article is licensed under a Creative Commons Attribution 4.0 International License, which permits use, sharing, adaptation, distribution and reproduction in any medium or format, as long as you give appropriate credit to the original author(s) and the source, provide a link to the Creative Commons licence, and indicate if changes were made. The images or other third party material in this article are included in the article's Creative Commons licence, unless indicated otherwise in a credit line to the material. If material is not included in the article's Creative Commons licence and your intended use is not permitted by statutory regulation or exceeds the permitted use, you will need to obtain permission directly from the copyright holder. To view a copy of this licence, visit http://creativecommons.org/licenses/by/4.0/. The Creative Commons Public Domain Dedication waiver (http://creativeco mmons.org/publicdomain/zero/1.0/) applies to the data made available in this article, unless otherwise stated in a credit line to the data. 
Keywords: Quality of life, Paroxysmal nocturnal hemoglobinuria, Clinical trial, Response shift, Patient-reported outcome, EORTC, Norms, Eculizumab, Ravulizumab

\section{Introduction}

Paroxysmal nocturnal hemoglobinuria $(\mathrm{PNH})$ is a rare and life-threatening hematologic disorder with significant morbidity and premature mortality [1]. People with PNH may present with hemoglobinuria, thrombosis, impaired kidney function, abdominal pain, dysphagia, pulmonary hypertension, chest pain, dyspnea, erectile dysfunction in males, end organ damage, and/or severe fatigue [2-7]. PNH is characterized by dysregulation of the terminal complement pathway, leading to intravascular hemolysis and thrombosis. Such patients generally have a poor quality of life (QOL) [8]. If untreated, up to $35 \%$ die within 5 years of diagnosis [2, 3, 9-13]. Although onset can occur at any age, $\mathrm{PNH}$ has a worldwide mean age of diagnosis of 39.3 years $(\mathrm{SD}=18.6)$ [2, 3, 14-16]. The prevalence rate is $12-13$ per $1,000,000$ persons and is similar across sexes but higher among older adults [17]. Its clinical course is highly unpredictable [3, 7]. Some patients have sudden onset and rapid progression to death, whereas others have long-term chronic illness but few life-threatening complications [3].

Eculizumab is a complement component-5 (C5) inhibitor that has been the standard of care since 2007, with evidence of lower mortality [18], improved QOL [19], reduced thrombosis risk, and normal life expectancy $[9,10,12,20]$. Because of the treatment burden $[21,22]$ imposed by biweekly doses of eculizumab, recent clinical trials compared it with ravulizumab. Ravulizumab is a recently ${ }^{1}$ developed $\mathrm{C} 5$ inhibitor that produces immediate, complete, and sustained inhibition of $\mathrm{C} 5$ with an extended, 8-week dosing interval. Two head-to-head randomized clinical trials documented the non-inferiority, safety, tolerability and efficacy of the two drugs. Trial 301 (ALXN1210-PNH-301) [22] was implemented in people with PNH naïve to complement inhibitors [22]; Trial 302 (ALXN1210-PNH-302) [21], in people with PNH who were stable on eculizumab for at least 6 months and of which half were randomized to switch to ravulizumab [21]. The most frequently reported adverse event was headache, with slightly higher rates for ravulizumab [21].

One important indicator of treatment effectiveness is whether the treatment can enable a normal QOL; however, "normal" or near-normal levels is a "high bar" for conditions like PNH. It is a particularly challenging question because there is no validated disease-specific patient-reported outcome (PRO) measure for $\mathrm{PNH}$

${ }^{1}$ FDA Dec 2018, EMA July 2019.
[23]. Because PNH's QOL impacts are similar to those of hematologic cancers, the pivotal trials collected data on cancer-specific QOL measures. Published results reported no difference between the treatments on the Functional Assessment of Chronic Illness (FACIT)Fatigue $[21,22]$ and showed improvements on the European Organisation for Research and Treatment of Cancer (EORTC)-QLQ-C30 Global Health Status/QOL score [22]. Understanding how PNH EORTC scores compare to general-population values would be important for characterizing the QOL impact of ravulizumab and eculizumab.

A substantial evidence base of research across a broad range of patient populations has documented that people living with chronic or terminal illness evaluate their QOL differently than the general population does [24-42]. These response-shift effects reflect changes in their internal standards, values and/or conceptualization of QOL over time $[43,44]$. Such changes might, for example, lead to a different way of thinking about "moderate" versus "little" fatigue compared to someone who has never had this blood disease (i.e., recalibration or change in internal standards). They may change their ideas of what is important to role functioning [45], for example, leading to different priorities and thus a different perspective on how well they are functioning (i.e., reprioritization or change in values) [40]. They may change the way they define QOL, for example by focusing less on economic or professional achievements and more on family welfare or intimacy (i.e., reconceptualization or change in conceptualization) [46]. Response-shift effects are natural and common concomitants to treatment outcomes [47-49]. When adaptive, they can help people maintain a homeostasis or stability in QOL that enables better affective and eudemonic well-being [50,51].

We hypothesize that PNH patients whose condition is well-managed will evidence response-shift effects. Evaluating response-shift effects is akin to studying an iceberg: one notices the portion that stands out from the surface (e.g., surprising or paradoxical findings), and then examines indicators of what is below to characterize the object's nature and size (e.g., information about differences in correlations among variables, item-response parameters, or cognitive-appraisal processes).

The present study thus evaluated the impact of ravulizumab and eculizumab on patients' QOL as measured by the EORTC QLQ-C30 after 26 weeks of treatment, as compared to general-population norms. This treatment period is generally accepted as sufficient to achieve 
a stable, well-managed condition. The present work thus provides a normative comparison by examining the same PRO in people with PNH and the general population. The study then investigated response-shift effects by examining differential item functioning (DIF) [52] - by treatment, by group as compared to the general population, and over time, the latter two suggesting and reflecting response-shift effects.

\section{Methods \\ Sample}

This post-hoc secondary analysis utilized three data sources: two PNH clinical trials and one general-population study. Both trials were phase-3, open-label studies evaluating the non-inferiority of ravulizumab compared to eculizumab in changing primary and secondary clinical endpoints. Trial 301 (ALXN1210-PNH-301) was implemented in people with $\mathrm{PNH}$ not previously treated with complement inhibitors [22]; Trial 302 (ALXN1210PNH-302), in people with PNH who were stable on eculizumab for at least 6 months and of whom half were randomized to switch to ravulizumab [21]. Data available for analysis included longitudinal follow-up from baseline through the extension trials, at which time all participants received ravulizumab, with total follow-up time typically 12 months (mean $=11.9$; $\mathrm{SD}=2.2$; range $=0.3-$ 19.4. For complete details on trial inclusion and exclusion criteria and procedures see references [21, 22]) The trial was conducted in accordance with the provision of the Declaration of Helsinki, the International Conference on Harmonization guidelines for Good Clinical Practice, and applicable regulatory requirements. The trial was approved by the institutional review board at each participating institution. All the patients provided written informed consent before participating.

The general-population study provided a 2015 crosssectional sample from 11 European countries. Further country-specific norm data were obtained from Russia, Turkey, Canada, and the United States. Ethical approval was not sought as this study was solely based on panel research data collected by GfK SE. The survey conformed to the required ethical standards by obtaining written informed consent from all participants and collecting data completely anonymously [53].

\section{Measures}

The EORTC QLQ-C30 is a comprehensive cancer-specific measure containing 30 items covering five function subscales (physical, role, emotional, cognitive, social); nine symptom subscales/items (fatigue, nausea/vomiting, pain, dyspnea, insomnia, appetite loss, constipation, diarrhea, financial difficulties); and a global health status/ QOL subscale $[54,55]$. Higher scores on the function and global health status/QOL scales and lower scores on the symptom scales reflect better health/QOL [56]. Of note, each individual item's response options, except those for global health status/QOL, moved toward worsening health, which will be specifically relevant for selected analyses.

Demographic characteristics collected for all datasets included age, sex, and region. From the trial datasets, baseline clinical variables included in the analysis were lactate dehydrogenase or LDH stratum $(<1.5 \times$ upper limit of normal [ULN]; $1.5-<3 \times \mathrm{ULN}$; or $\geq 3 \times \mathrm{ULN})$; pRBC stratum (0 units; $1-14$; or $>14$ ), and binary flags for aplastic anemia, immunosuppressant treatment, myelodysplastic syndrome, and bone marrow disorder.

\section{Statistical analysis}

Analyses were conducted for the overall PNH group versus general population and by $\mathrm{PNH}$ risk-factor group. Risk-factor groups were created based on clinical indicators known to be associated with worse PNH outcomes (Table 1). An initial risk-factor score was based on a weighted sum of these indicators. The binary flags were given a weight of one (i.e., no $=1$, yes $=2$ ), whereas the LDH stratum was given a higher weight (i.e., stratum $1=2$; stratum $2=4$, stratum $3=6$ ). Since $\mathrm{pRBC}$ was not used in the 302 trial, it was not included among the clinical indicators used for the risk-factor score. This weighting approach was based on input from a knowledgeable PNH clinician (AGK). The resulting score ranged from 6 to 12 , and it was used to create a lower-risk-factor group (score 6-8) and a higher-risk-factor group (score 9-12).

Multivariate Analysis of Covariance (MANCOVA) compared people with $\mathrm{PNH}$ on ravulizumab or eculizumab after 26 weeks to the general-population sample. Group was coded such that those on ravulizumab and eculizumab were each compared to the general population, the referent group. Dependent variables for a first model included function and global-QOL scale scores, and for a second model, symptom scale scores/items. Age, sex, and region were included as covariates. MANCOVAs were also computed separately for lower and higher $\mathrm{PNH}$ risk-factor groups as a way of adjusting for PNH severity.

Similar MANCOVA models were also computed by PNH-risk-factor group at baseline to check that results of the above models were likely results of treatment rather than of preexisting characteristics of the study samples.

Because the general-population sample was disproportionately large, model results are reported in terms of Cohen's $d$ statistic [57], expressed in standard-deviation units, to emphasize the degree to which group differences may have been clinically important. Using Cohen's criteria, a $d$ of $0.2-0.49$ is considered a small effect size, $0.5-$ 0.79 is medium, and 0.8 or greater is large [57]. 
Table 1 Deriving the PNH risk-factor score

\begin{tabular}{|c|c|c|}
\hline Clinical indicator & Specific level of clinical indicator & Assigned value \\
\hline \multirow[t]{3}{*}{ Observed LDH category } & $\mathrm{LDH}<1.5 \times \mathrm{ULN}$ & 2 \\
\hline & $\mathrm{LDH} 1.5-<3 \times$ ULN & 4 \\
\hline & $\mathrm{LDH} \geq 3 \times \mathrm{xUN}$ & 6 \\
\hline \multirow[t]{3}{*}{ Observed pRBC stratum } & 0 unit pRBC & NA \\
\hline & $1-14$ units $p R B C$ & NA \\
\hline & $>14$ units $\mathrm{pRBC}$ & NA \\
\hline \multirow[t]{2}{*}{ Immuno-suppressant treatment } & No & 1 \\
\hline & Yes & 2 \\
\hline \multirow[t]{2}{*}{ Aplastic anemia } & No & 1 \\
\hline & Yes & 2 \\
\hline \multirow[t]{2}{*}{ Myelodysplastic syndrome } & No & 1 \\
\hline & Yes & 2 \\
\hline \multirow[t]{2}{*}{ Bone marrow disorder } & No & 1 \\
\hline & Yes & 2 \\
\hline \multicolumn{3}{|l|}{ Summary score creation } \\
\hline Sum all assigned values & $\begin{array}{l}\text { Sum assigned values for observed LDH, Immuno-suppressant treatment, aplastic } \\
\text { anemia, myelodysplastic syndrome, and bone marrow disorder }\end{array}$ & \\
\hline \multicolumn{3}{|l|}{ Create $\mathrm{PNH}$ risk-factor group } \\
\hline & Lower & $6-8$ \\
\hline & Higher & $9-12$ \\
\hline
\end{tabular}

NA: Since $p R B C$ was not used in the 302 trial, it was not included among the clinical indicators used for the risk-factor score

Heat maps were used to illustrate group differences by computing this same effect size using means and standard deviations by age and gender groupings. Formatting of tables and figures illustrates effect-size magnitude, with more saturated color indicating larger effect.

Past research on item response and response shift have built on structural equation models [41] or item response theory (IRT) models [42]. Here, initial efforts used a bifactor model for the function scores (poor model fit) and multidimensional IRT models for function and symptom scores (models did not converge due to identifiability problems). The present work thus utilized a logistic-regression framework to test for DIF [43]. Accordingly, we adapted response-shift operationalizations by building upon this prior work.

In this study, recalibration response shift is operationalized as uniform DIF over time, because it reflects the idea that, for a given group, the difficulty of endorsing an item may change over time, after adjusting for the total subscale score (i.e., the latent trait). For example, uniform DIF would reflect a specific emotional-functioning item being easier or harder to endorse than one might expect, given a certain level of overall emotional functioning.

Reprioritization response shift is operationalized as non-uniform DIF over time because the relative difficulty of endorsing an item over time may change across the total score on the domain. This type of response shift is captured by item discrimination or slope. For example, non-uniform DIF would reflect a specific emotionalfunctioning item becoming easier or harder to endorse over time than one might expect, given a certain trajectory of overall emotional functioning.

DIF analyses [58,59] were conducted on the 24 EORTC QLQ-C30 items belonging to scales with at least two items. The basic DIF analyses used ordinal logistic regression and involved building three nested models:

Model 1: $\operatorname{Logit}[\mathrm{P}(\mathrm{Y} \leq \mathrm{j})]=\alpha_{\mathrm{j}}+b_{1}($ Total Score $)$

Model 2: $\operatorname{Logit}[\mathrm{P}(\mathrm{Y} \leq \mathrm{j})]=\alpha_{\mathrm{j}}+b_{1}($ Total Score $)+b_{2}$ (Group); and

Model 3: $\operatorname{Logit}[\mathrm{P}(\mathrm{Y} \leq \mathrm{j})]=\alpha_{\mathrm{j}}+b_{1}($ Total Score $)+b_{2}$ (Group) $+b_{3}$ (Total Score * Group),

where $\mathrm{P}(\mathrm{Y} \leq \mathrm{j})$ represents the probability that $j$ is the rating-scale response category, each $\alpha_{\mathrm{j}}$ is a regression constant, and each $b$ is a regression coefficient. ${ }^{2}$

The log-likelihood ratio test for statistical significance compared Model 1 versus 2, Model 2 versus 3, and Model 1 versus 3 . Uniform DIF is characterized by $b_{2}$ being

\footnotetext{
${ }^{2}$ Technical note: The standard ordinal logistic regression model parameterization indicates the probability of moving to a lower category for each unit increase in $X$. Stata transforms the output such that positive coefficients indicate higher probabilities of moving to a "higher" category for each unit increase in $X$, easing interpretation.
} 
significant and the log-likelihood test comparing Models 1 and 2 being significant (i.e., there is a significant main effect for Group). Non-uniform DIF is characterized by $\mathrm{b}_{3}$ being significant and the log-likelihood test comparing Models 2 and 3 being significant (i.e., there is a significant Group-by-total score interaction). Uniform and Non-uniform DIF is characterized by the log-likelihood test comparing Models 1 and 3 being significant.

DIF was computed in three ways to test distinct hypotheses, which tested one alternative explanation (first hypothesis) prior to testing for more definitive evidence of response-shift effects (second and third hypothesis, respectively):

DIF by treatment compared ravulizumab and eculizumab groups on item difficulty (threshold) and item discrimination (slope) in the longitudinal data. If significant, this type of DIF would suggest that the two treatment groups are responding differently to the EORTC items, and thus one cannot validly compare their responses.

DIF by group compared people with $\mathrm{PNH}$ to the general-population group at one point in time: after 26 weeks on therapy and at the single time point collected in the general-population study. In this analysis, domain scores were first grand-mean-centered to aid interpretation. When uniform DIF was detected, the associated odds ratio indicated the "favored" group: when $>1.0$, the PNH group was more likely than expected to endorse (i.e., endorsing was "easier"); when $<1.0$, the PNH group was less likely than expected to endorse (i.e., endorsing was "harder"). If the associated log-likelihood test's $p$ value was significant (i.e., < 0.05 ), this type of DIF showed that the groups were responding differently to the items. The use of the term "harder" reflects the centrality of the idea of difficulty in the study of item response. Greater item difficulty would mean a higher bar for endorsing a particular response option, given one's total score on that domain. Such systematic differences between people with $\mathrm{PNH}$ and the general population would suggest that the two groups do not have a similar contingent true score, meaning that they are thinking about the QOL item(s) differently in terms of frame of reference, sampling of experience, standards of comparison, or patterns of emphasis. Fuller explanation of these concepts can be found in $[46,49]$. Because the data testing this DIF hypothesis are measured at one point in time, response shift is not a definitive explanation and would require longitudinal data for confirmation.

DIF over time compared, for people with $\mathrm{PNH}$, slopes and thresholds over the course of the pivotal and extension trials, to test for intra-individual changes. If significant, this type of DIF provides further support for recalibration and reprioritization response-shift effects. This DIF would demonstrate that individuals with $\mathrm{PNH}$ change the cognitive-appraisal processes underlying their item response, i.e., that their contingent true score changes over time.

Multilevel modeling was used to account for the multiple data points per person used for the DIF-by-treatment and DIF-over-time analyses. SPSS Release 27 [60] and Stata/IC 16.1 [61] were used for all analyses.

\section{Results \\ Sample}

The study samples included 441 people with $\mathrm{PNH}$, of whom 246 had participated in trial 301 and 195 in trial 302. In trial 301, 214 people were on eculizumab and 224 on ravulizumab. In trial 302, 107 people were on eculizumab and 111 on ravulizumab. The PNH group was further characterized as 224 with lower and 217 higher levels of risk factors. The EORTC sample included 15,386 people. Table 2 provides descriptive statistics on demographic information shared between the two study samples. Table 3 provides clinical information about the $\mathrm{PNH}$-treatment groups.

\section{QOL comparison after 26 weeks}

MANCOVA models revealed that across levels of PNH risk factors, patients who had been on either ravulizumab or eculizumab for 26 weeks reported better physical, emotional, and cognitive functioning, and lower nausea/ vomiting, pain, insomnia, appetite loss, constipation, and diarrhea symptoms, than the general population, after adjusting for covariates (Table 4). Additionally, ravulizumab patients reported higher global health status/ QOL, lower fatigue, and lower financial difficulties than the general population (Table 4). The effect sizes were generally larger for the ravulizumab patients.

MANCOVA models conducted separately by risk level revealed further nuances in QOL after treatment. Similar to the overall MANCOVA, compared to the general population, both eculizumab and ravulizumab lower-riskfactor patients reported higher physical and emotional functioning and lower nausea/vomiting, pain, insomnia, appetite loss, constipation, and diarrhea symptoms. Further, the lower-risk-factor ravulizumab patients also reported better cognitive functioning and global QOL, and lower fatigue, dyspnea, and financial difficulties. In several domains, the effect sizes were larger for these ravulizumab patients (Table 4).

Models focused on the higher-risk-factor patients as compared to the general population revealed that people with PNH reported better emotional and cognitive functioning, and lower fatigue, pain, insomnia, constipation, and diarrhea (Table 4). Further, these ravulizumab patients also reported better physical and social functioning, and lower symptom burden in nausea/vomiting 
Table 2 Demographics of PNH patients at baseline compared to general population

\begin{tabular}{|c|c|c|c|c|c|c|}
\hline \multirow[t]{2}{*}{ Variable } & \multicolumn{2}{|c|}{ Began trial on eculizumab $(n=219)$} & \multicolumn{2}{|c|}{ Began trial on ravulizumab $(n=222)$} & \multicolumn{2}{|c|}{$\begin{array}{l}\text { General population } \\
(n=15,386)\end{array}$} \\
\hline & Mean & SD & Mean & SD & Mean & SD \\
\hline Age & 47.38 & 15.30 & 45.67 & 14.83 & 53.57 & 15.375 \\
\hline Years Since Diagnosis & 8.93 & 8.84 & 9.33 & 8.70 & NA & \\
\hline \multirow[t]{2}{*}{ Baseline BMI $\left(\mathrm{kg} / \mathrm{m}^{2}\right)$} & 25.25 & 4.23 & 24.83 & 4.71 & & \\
\hline & $\#$ & $\%$ & $\#$ & $\%$ & $\#$ & $\%$ \\
\hline \multicolumn{7}{|l|}{ Region } \\
\hline Europe & 113 & 51.60 & 106 & 47.75 & 13,373 & 86.92 \\
\hline Japan & 22 & 10.05 & 25 & 11.26 & 0 & 0.00 \\
\hline Latin America & 13 & 5.94 & 9 & 4.05 & 0 & 0.00 \\
\hline North America & 16 & 7.31 & 17 & 7.66 & 2013 & 13.08 \\
\hline Rest of Asia Pacific & 55 & 25.11 & 65 & 29.28 & 0 & 0.00 \\
\hline Female & 102 & 46.58 & 107 & 48.20 & 7650 & 49.72 \\
\hline
\end{tabular}

Table 3 Clinical characteristics of PNH patients at baseline

\begin{tabular}{|c|c|c|c|c|c|c|c|c|}
\hline \multirow[t]{3}{*}{ Variable } & \multicolumn{4}{|c|}{ Began trial on eculizumab $(n=219)$} & \multicolumn{4}{|c|}{ Began trial on ravulizumab $(n=222)$} \\
\hline & \multicolumn{2}{|c|}{ Trial 301} & \multicolumn{2}{|c|}{ Trial 302} & \multicolumn{2}{|c|}{ Trial 301} & \multicolumn{2}{|c|}{ Trial 302} \\
\hline & $\#$ & $\%$ & $\#$ & $\%$ & $\#$ & $\%$ & $\#$ & $\%$ \\
\hline \multicolumn{9}{|l|}{ Observed LDH Category } \\
\hline $\mathrm{LDH}<1.5 \times \mathrm{ULN}$ & 0 & 0 & 98 & 100 & 0 & 0 & 97 & 100 \\
\hline LDH $1.5-<3 \times U L \mathrm{LN}$ & 16 & 13 & 0 & 0 & 18 & 14 & 0 & 0 \\
\hline $\mathrm{LDH} \geq 3 \times \mathrm{ULN}$ & 105 & 87 & 0 & 0 & 107 & 86 & 0 & 0 \\
\hline \multicolumn{9}{|l|}{ Observed pRBC stratum } \\
\hline 0 unit $\mathrm{pRBC}$ & 21 & 17 & NA & & 22 & 18 & NA & \\
\hline $1-14$ units $p R B C$ & 76 & 63 & & & 80 & 64 & & \\
\hline$>14$ units $p R B C$ & 24 & 20 & & & 23 & 18 & & \\
\hline Immuno-suppressant treatment & 14 & 12 & 98 & 100 & 15 & 12 & 97 & 100 \\
\hline Aplastic anemia & 38 & 31 & 39 & 40 & 41 & 33 & 34 & 35 \\
\hline Myelodysplastic syndrome & 6 & 5 & 6 & 6 & 7 & 6 & 3 & 3 \\
\hline Bone marrow disorder & 43 & 36 & 42 & 43 & 46 & 37 & 35 & 36 \\
\hline \multicolumn{9}{|l|}{ Derived PNH risk-factor group } \\
\hline Higher & 107 & 88 & 0 & 0 & 110 & 88 & 0 & 0 \\
\hline \multirow[t]{2}{*}{ Lower } & 14 & 12 & 98 & 100 & 15 & 12 & 97 & 100 \\
\hline & Mean & SD & Mean & SD & Mean & SD & Mean & SD \\
\hline Derived PNH risk-factor index & 9.21 & 0.93 & 6.46 & 0.56 & 9.22 & 0.87 & 6.38 & 0.53 \\
\hline
\end{tabular}

and appetite loss (Table 4). In almost all cases, these ravulizumab patients had larger effect sizes than the eculizumab patients (Table 4).

Figure 1a and b show heat maps comparing treated patients to general-population norms. Since all of the differences showed better scores for the $\mathrm{PNH}$ group (i.e., higher on function/global QOL scales, lower on symptom scales/items), only one color is used for the conditional formatting. These graphs suggest that generally the effects were larger for the function scales than for the symptom scales/items and larger for ravulizumab patients than for eculizumab patients. 
Table 4 Effect sizes: PNH patients after 26 weeks of treatment compared to general population

\begin{tabular}{|c|c|c|c|c|c|c|c|}
\hline & \multicolumn{2}{|c|}{ Overall PNH } & \multicolumn{2}{|c|}{ Lower PNH risk factors } & \multicolumn{2}{|c|}{ Higher PNH risk factors } & \\
\hline & $\begin{array}{c}\text { Ecu } \\
(N=214)\end{array}$ & $\begin{array}{c}\text { Ravu } \\
(\mathrm{N}=224)\end{array}$ & $\begin{array}{c}\text { Ecu } \\
(\mathrm{N}=107)\end{array}$ & $\begin{array}{c}\text { Ravu } \\
(\mathrm{N}=111)\end{array}$ & $\begin{array}{c}\text { Ecu } \\
(\mathrm{N}=105)\end{array}$ & Ravu (N=110) & \\
\hline \multicolumn{7}{|c|}{ Function scores (higher is better) } & \\
\hline Physical functioning & 0.20 & 0.35 & 0.30 & 0.36 & 0.02 & 0.26 & \\
\hline Role functioning & -0.02 & 0.14 & -0.01 & 0.13 & -0.03 & 0.13 & \\
\hline Emotional functioning & -0.61 & 0.90 & 0.46 & 0.80 & 0.91 & 1.07 & \\
\hline Cognitive functioning & 0.21 & 0.36 & 0.17 & 0.34 & 0.28 & 0.39 & \\
\hline Social functioning & -0.01 & 0.18 & 0.07 & 0.11 & -0.10 & 0.25 & \\
\hline Global health status/QOL & 0.17 & 0.41 & 0.19 & 0.64 & 0.08 & 0.13 & \\
\hline \multicolumn{7}{|c|}{ Symptom scores (higher is worse) } & \\
\hline Fatigue & -0.18 & -0.31 & -0.10 & -0.30 & -0.32 & -0.34 & \\
\hline Nausea and vomiting & -0.27 & -0.38 & -0.37 & -0.27 & -0.19 & -0.76 & \\
\hline Pain & -0.81 & -0.94 & -0.69 & -0.85 & -1.02 & -1.06 & \\
\hline Dyspnea & 0.08 & -0.06 & 0.08 & -0.22 & 0.14 & 0.16 & \\
\hline Insomnia & -0.43 & -0.56 & -0.31 & -0.64 & -0.60 & -0.47 & \\
\hline Appetite loss & -0.22 & -0.44 & -0.27 & -0.40 & -0.19 & -0.49 & \\
\hline Constipation & -0.35 & -0.39 & -0.28 & -0.27 & -0.49 & -0.62 & \\
\hline Diarrhea & -0.35 & -0.54 & -0.47 & -0.38 & -0.29 & -0.78 & \\
\hline Financial difficulties & -0.03 & -0.20 & -0.16 & -0.27 & 0.12 & -0.07 & \\
\hline
\end{tabular}

Conditional formatting shows the magnitude and direction (green = better health status; red = worse health status) of the adjusted mean differences. General Population $\mathrm{N}=15,386$.

\section{QOL comparison at baseline}

Because many of these findings were counter to expectation (i.e., functioning and symptom scores that were better than in the general population), we implemented similar MANCOVAs using the baseline data of trial patients who were treatment-naïve (from trial 301), to check whether the results were more likely due to treatment or to stable participant characteristics. These sample sizes are substantially smaller due to excluding patients from trial 302 while also splitting the analysis by level of risk. Results show that in general and as expected, untreated people with $\mathrm{PNH}$ at baseline reported worse function and symptom scores than did the general population. The exceptions generally involved small effects. (Additional file 1: Table S1).

\section{DIF by treatment}

Results of multilevel DIF analysis by treatment group revealed no significant effects in any of the 24 EORTC QLQ-C30 items (Table 5). Thus, across the multiple time points, there is no indication of treatment-related DIF, and one can compare responses of people with PNH regardless of the treatment they have received. In other words, given the same total score, people in the two groups responded similarly to a given item in that scale.

\section{DIF by group}

Results of PNH versus general-population groups' DIF analysis revealed uniform DIF in 14 items (Table 6). Most often it was more difficult for the treatment group to report that they had poor health. This was true for 9 of these items ( 1 physical item, 2 emotional, 1 cognitive, 2 social, 1 fatigue, 1 nausea, and 1 pain). In 5 of these items (1 physical, 1 emotional, 1 cognitive, 1 fatigue, 1 nausea), it was more difficult for the general-population group to report poorer health.

Non-uniform DIF was detected in 11 items, 6 favoring the general population at the domain score mean, meaning that it was easier for them to report poorer health (1 physical, 1 emotional, 1 cognitive, 2 social, 1 nausea), suggesting that this group effect varied by level of the EORTC QLQ-C30 item. There were 5 items favoring the $\mathrm{PNH}$ group, meaning that it was easier for them to report poorer health (1 physical, 1 emotional, 1 cognitive, 1 fatigue, and 1 pain).

\section{DIF over time}

Results of multilevel DIF analysis evaluating the impact of time on people with $\mathrm{PNH}$ item responses revealed significant uniform DIF effects in 7 of the 24 items (Table 7). These differences related to physical function ( 2 of 5 items), role function (2 of 2), emotional function (1 of 4), fatigue 


\section{a}

\begin{tabular}{|c|c|c|c|c|c|c|c|c|c|c|c|c|c|c|c|}
\hline & \multicolumn{15}{|c|}{ Ravulizumab, After 26 Weeks of Treatment: Effect Size for Difference (Trial Sample - Norm) ( $N=427)^{*}$} \\
\hline & \multirow[b]{2}{*}{ Total } & \multicolumn{7}{|c|}{ Female } & \multicolumn{7}{|c|}{ Male } \\
\hline & & All $\mathrm{F}$ & $18-29$ & $30-39$ & $40-49$ & $50-59$ & $60-69$ & $\geq 70$ & All $M$ & $18-29$ & 30-39 & $40-49$ & $50-59$ & $60-69$ & $\geq 70$ \\
\hline Physical function & .2 & .1 & .1 & .2 & -.1 & .0 & .0 & .0 & .4 & .8 & .4 & .2 & .5 & -.1 & .1 \\
\hline Role function & .1 & .0 & -.2 & .2 & .0 & -.1 & -.2 & .1 & .2 & .6 & .4 & .1 & .3 & -.2 & .0 \\
\hline Emotional function & .6 & .6 & .6 & 1.0 & .7 & .4 & .3 & .5 & .7 & 1.0 & 1.0 & .6 & 1.0 & .2 & .4 \\
\hline Cognitive function & .2 & .0 & .3 & .1 & .1 & -.1 & .0 & -.1 & .3 & 1.0 & .4 & .2 & .2 & .0 & .4 \\
\hline Social function & .1 & .1 & .4 & .2 & .2 & .0 & -.1 & -.2 & .2 & .5 & .5 & .0 & .3 & -.1 & .2 \\
\hline Global health / QOL & .2 & .2 & .3 & .4 & .3 & .1 & -.2 & .1 & .3 & .4 & .3 & .5 & .4 & -.2 & -.3 \\
\hline Fatigue & -.3 & -.2 & -.4 & -.4 & -.3 & -.1 & .1 & -.1 & -.4 & -1.0 & -.6 & -.4 & -.6 & .2 & .2 \\
\hline Nausea/vomiting & -.3 & -.2 & -.2 & -.5 & -.2 & -.1 & .0 & -.1 & -.4 & -.6 & -.6 & -.4 & -.1 & -.1 & .0 \\
\hline Pain & -.7 & -.6 & -.5 & -.8 & -.4 & -.5 & -.7 & -.6 & -.8 & -1.3 & -.9 & -.6 & -.9 & -.5 & -.8 \\
\hline Dyspnoea & -.1 & .0 & .0 & .0 & -.1 & .1 & .0 & .1 & -.2 & -.5 & -.3 & .0 & -.4 & .1 & .5 \\
\hline Insomnia & -.4 & -.4 & -.4 & -.6 & -.4 & -.5 & -.1 & -.2 & -.5 & -.5 & -.9 & -.5 & -.9 & .1 & .0 \\
\hline Appetite loss & -.3 & -.2 & -.3 & -.6 & -.1 & -.3 & .2 & .0 & -.3 & -.7 & -.4 & -.3 & -.3 & .1 & -.3 \\
\hline Constipation & -.3 & -.3 & -.3 & -.8 & -.5 & .1 & -.2 & -.2 & -.3 & -.7 & -.1 & -.3 & -.2 & -.2 & -.3 \\
\hline Diarrhoea & -.3 & -.3 & -.3 & -.6 & -.2 & -.2 & .0 & -.8 & -.3 & -.5 & -.5 & -.1 & -.2 & -.2 & -.2 \\
\hline Financial difficulties & .0 & -.1 & -.2 & -.3 & .0 & .0 & .0 & .1 & .0 & -.4 & .0 & .2 & .1 & .0 & -.1 \\
\hline
\end{tabular}

*Includes people with PNH on ravulizumab after 26 weeks either during the randomized period or during the extension-trial period. This meant assessment at 52 weeks for patients who had eculizumab for 26 weeks and then had ravulizumab for 26 weeks.

Includes Trial $301(N=242)$ and $302(N=185)$.

Fig. 1 Heat maps. Heat maps illustrate group differences for ravulizumab (a) and eculizumab (b) using Cohen's $d$ effect size computed from aggregated means and standard deviations by age and gender groupings. Conditional formatting illustrates effect-size magnitude with a more saturated color reflecting larger effect size. Since all of the differences were in the direction of PNH group scoring better than the general population (i.e., higher on function/global QOL scales, lower on symptom scales/items), only one color is used for the conditional formatting. Figure a includes people with PNH on ravulizumab after 26 weeks either during the randomized period or during the extension-trial period. This meant assessment at 52 weeks for patients who had eculizumab for 26 weeks and then had ravulizumab for 26 weeks. Includes Trial 301 ( $N=242$ ) and 302 $(\mathrm{N}=185)$. Figure $\mathbf{b}$ includes people with PNH who had been on eculizumab for 26 weeks. All these patients' assessments were made during the randomized period. Includes Trial $301(\mathrm{~N}=118)$ and $302(\mathrm{~N}=95)$

(1 of 3 ), and pain (1 of 2$)$. These DIF effects suggested a decreasing likelihood over time of endorsing physical function problems, fatigue, and pain symptoms, given their total scores on the corresponding scales. In contrast, there was an increasing likelihood of endorsing irritability (emotional function item). For the two role-function items, one result showed an increase and one a decrease, thereby canceling each other out. Three of 24 items showed evidence of nonuniform DIF: 1 emotional, 1 fatigue, and 1 pain. Thus, there is evidence of recalibration response-shift effects in 7 of 24 items, and reprioritization response-shift effects in 3 items.

\section{Discussion}

This study revealed that people with $\mathrm{PNH}$ on eculizumab and especially ravulizumab for 26 weeks reported QOL levels better than those of the general population, typically by 0.3 standard deviations. Not only was ravulizumab not inferior to eculizumab [21, 22], but both 
b

\begin{tabular}{|c|c|c|c|c|c|c|c|c|c|c|c|c|c|c|c|}
\hline & \multicolumn{15}{|c|}{ Eculizumab, After 26 Weeks of Treatment: Effect Size for Difference (Trial Sample - Norm) $(\mathrm{N}=213)$} \\
\hline & \multirow[b]{2}{*}{ Total } & \multicolumn{7}{|c|}{ Female } & \multicolumn{7}{|c|}{ Male } \\
\hline & & All $\mathrm{F}$ & $18-29$ & 30-39 & 40-49 & 50-59 & $60-69$ & $\geq 70$ & All $M$ & $18-29$ & 30-39 & 40-49 & 50-59 & 60-69 & $\geq 70$ \\
\hline Physical function & .2 & .1 & .0 & .0 & .2 & .1 & .2 & -.2 & .3 & .7 & .3 & .6 & .2 & -.2 & -.1 \\
\hline Role function & .1 & .0 & -.2 & -.3 & .1 & .1 & .3 & -.2 & .2 & .6 & .2 & .2 & .2 & -.2 & .2 \\
\hline Emotional function & .6 & .6 & .9 & .6 & .6 & .6 & .8 & .0 & .6 & .8 & .8 & .4 & 1.1 & .2 & -.1 \\
\hline Cognitive function & .2 & .0 & .3 & -.1 & .2 & .2 & .1 & -.6 & .3 & 1.1 & .3 & .3 & .4 & .0 & .1 \\
\hline Social function & .0 & .0 & -.2 & -.1 & .3 & .2 & .2 & -.6 & .0 & .6 & .0 & .1 & .0 & -.2 & -.4 \\
\hline Global health / QOL & .1 & .1 & .2 & -.2 & .3 & .3 & .2 & -.3 & .1 & .3 & .2 & .1 & .5 & -.1 & -.3 \\
\hline Fatigue & -.3 & -.2 & -.5 & .0 & -.3 & -.2 & -.1 & .0 & -.4 & -.9 & -.7 & -.4 & -.5 & .2 & -.1 \\
\hline Nausea/vomiting & -.2 & -.1 & -.3 & .0 & -.2 & -.2 & -.1 & .1 & -.4 & -1.0 & -.6 & -.2 & -.1 & .1 & .2 \\
\hline Pain & -.7 & -.6 & -.8 & -.2 & -.4 & -.9 & -1.1 & -.4 & -.7 & -.9 & -.8 & -.6 & -.7 & -.5 & -1.1 \\
\hline Dyspnoea & .0 & .1 & -.2 & .2 & .0 & .2 & .0 & .4 & -.2 & -.5 & -.4 & -.5 & -.2 & .4 & .4 \\
\hline Insomnia & -.4 & -.4 & -.4 & .0 & -.5 & -.5 & -.5 & -.5 & -.5 & -.5 & -.7 & -.4 & -.8 & .1 & -.3 \\
\hline Appetite loss & -.2 & .0 & -.1 & -.1 & .1 & -.2 & .0 & .4 & -.3 & -.8 & -.6 & -.8 & -.1 & -.3 & .4 \\
\hline Constipation & -.3 & -.3 & -.4 & -.5 & -.4 & -.1 & -1.1 & .3 & -.3 & -1.1 & -.5 & -.2 & -.3 & .0 & .2 \\
\hline Diarrhoea & -.2 & -.2 & .1 & -.4 & -.9 & -.2 & .2 & -.8 & -.2 & -.3 & -.3 & -.1 & -.2 & -.8 & -.7 \\
\hline Financial difficulties & .1 & -.1 & .1 & -.3 & .0 & -.3 & -.8 & .5 & .3 & .0 & .3 & .2 & .5 & .1 & .4 \\
\hline
\end{tabular}

*Includes people with PNH who had been on eculizumab for 26 weeks. All these patients' assessments were during the randomized period.

Includes Trial $301(N=118)$ and $302(N=95)$.

Fig. 1 continued

treatments also appeared to make QOL with PNH at least as good as the norm. These findings were equally notable for lower- and higher-risk-factor patients. In contrast, at baseline and prior to treatment, people with $\mathrm{PNH}^{3}$ especially those categorized with higher-risk-factor $\mathrm{PNH}$, were generally worse off than the general population.

DIF analyses revealed group- and time-related DIF, but not treatment-related DIF. Thus, there were no systematic differences in item response between these two effective $\mathrm{PNH}$ treatments, but there were in analyses comparing people with $\mathrm{PNH}$ to the general population, and to themselves over time. Specifically, compared to the general population, people with $\mathrm{PNH}$ after 26 weeks

\footnotetext{
${ }^{3}$ In this analysis we only included patients from trial 301 as these patients were untreated at baseline, whereas patients in trial 302 were stable at trial entry.
}

of effective treatment tended to be less likely than expected to endorse poor health. For example, they were less likely to endorse having trouble concentrating than one might expect given their overall level of cognitive function (uniform DIF or recalibration). This effect for concentration was even more pronounced over levels of the trait (non-uniform DIF or reprioritization).

These recalibration and reprioritization effects reflect adaptive response shifts. In this way, the scores of people with $\mathrm{PNH}$, irrespective of treatment, not only approached "normal" QOL, but even "better than normal" This pattern of responses suggests that ravulizumab and eculizumab enabled patients not only to achieve a better QOL but also to adapt to their condition. For example, they may have been aware of being fatigued while at the same time noting that it was less debilitating than it used to be. 
Table 5 Results of DIF analyses by treatment group

\begin{tabular}{|c|c|c|c|c|c|c|}
\hline \multirow[t]{3}{*}{ Item } & \multirow[t]{3}{*}{ Label } & \multirow[t]{3}{*}{ Domain } & \multicolumn{4}{|c|}{ DIF by treatment group } \\
\hline & & & \multicolumn{2}{|c|}{ Test of uniform DIF } & \multicolumn{2}{|c|}{ Test of non-uniform DIF } \\
\hline & & & $\begin{array}{l}p \text { value } \\
\text { (on group } \\
\text { effect) }\end{array}$ & $\begin{array}{l}\text { "Favored"* } \\
\text { group }\end{array}$ & $\begin{array}{l}\text { Odds ratio on } \\
\text { group effect }\end{array}$ & $\begin{array}{l}p \text { value (on } \\
\text { interaction } \\
\text { term) }\end{array}$ \\
\hline eortc29 & 29. How would you rate your overall health during the past week? & Global & NS & NS & NS & NS \\
\hline eortc30 & $\begin{array}{l}\text { 30. How would you rate your overall quality of life during the past } \\
\text { week? }\end{array}$ & Global & NS & NS & NS & NS \\
\hline eortc01 & $\begin{array}{l}\text { 1. Do you have any trouble doing strenuous activities, like carrying } \\
\text { a heavy shopping bag or a suitcase? }\end{array}$ & Physical & NS & NS & NS & NS \\
\hline eortc02 & 2. Do you have any trouble taking a long walk? & Physical & NS & NS & NS & NS \\
\hline eortc03 & $\begin{array}{l}\text { 3. Do you have any trouble taking a short walk outside of the } \\
\text { house? }\end{array}$ & Physical & NS & NS & NS & NS \\
\hline eortc04 & 4. Do you need to stay in bed or a chair during the day? & Physical & NS & NS & NS & NS \\
\hline eortc05 & $\begin{array}{l}\text { 5. Do you need help with eating, dressing, washing yourself or } \\
\text { using the toilet? }\end{array}$ & Physical & NS & NS & NS & NS \\
\hline eortc06 & $\begin{array}{l}\text { 6. Were you limited in doing either your work or other daily activi- } \\
\text { ties? }\end{array}$ & Role & NS & NS & NS & NS \\
\hline eortc07 & $\begin{array}{l}\text { 7. Were you limited in pursuing your hobbies or other leisure time } \\
\text { activities? }\end{array}$ & Role & NS & NS & NS & NS \\
\hline eortc21 & 21. Did you feel tense? & Emotional & NS & NS & NS & NS \\
\hline eortc22 & 22. Did you worry? & Emotional & NS & NS & NS & NS \\
\hline eortc23 & 23. Did you feel irritable? & Emotional & NS & NS & NS & NS \\
\hline eortc24 & 24. Did you feel depressed? & Emotional & NS & NS & NS & NS \\
\hline eortc20 & $\begin{array}{l}\text { 20. Have you had difficulty in concentrating on things, like reading } \\
\text { a newspaper or watching television? }\end{array}$ & Cognitive & NS & NS & NS & NS \\
\hline eortc25 & 25. Have you had difficulty remembering things? & Cognitive & NS & NS & NS & NS \\
\hline eortc26 & $\begin{array}{l}\text { 26. Has your physical condition or medical treatment interfered } \\
\text { with your family life? }\end{array}$ & Social & NS & NS & NS & NS \\
\hline eortc27 & $\begin{array}{l}\text { 27. Has your physical condition or medical treatment interfered } \\
\text { with your social activities? }\end{array}$ & Social & NS & NS & NS & NS \\
\hline eortc10 & 10. Did you need to rest? & Fatigue & NS & NS & NS & NS \\
\hline eortc12 & 12. Have you felt weak? & Fatigue & NS & NS & NS & NS \\
\hline eortc18 & 18. Were you tired? & Fatigue & NS & NS & NS & NS \\
\hline eortc14 & 14. Have you felt nauseated? & Nauseau & NS & NS & NS & NS \\
\hline eortc15 & 15. Have you vomited? & Nauseau & NS & NS & NS & NS \\
\hline eortc09 & 9. Have you had pain? & Pain & NS & NS & NS & NS \\
\hline eortc19 & 19. Did pain interfere with your daily activities? & Pain & NS & NS & NS & NS \\
\hline
\end{tabular}

*"Favored" = Finds it easier to endorse poor health except for eortc29 and eortc30

Thus, compared to the general population, the same level of feeling heavy and lethargic may have been calibrated as less onerous for someone with PNH. This recalibration response shift would continue over time, making their earlier and later responses less-than-comparable because of differences in their contingent true score (e.g., comparing their QOL to different standards). As another related dynamic, they may have modified their daily responsibilities or hobbies, so that the activities were more feasible. In this new context, it would be more difficult for them to report that these activities were limited by their condition (reprioritization response shift).
PNH is a difficult disease to live with. Its many signs and symptoms involve multiple organ systems, and the uncertainty that people with $\mathrm{PNH}$ experience makes these function- and symptom-impacts even more challenging. A treatment that provides immediate, complete and sustained C5 inhibition not only brings QOL to a normal level, but it enables adaptation, which may have an even greater value. For someone who knows what debilitating fatigue is, being given the opportunity to experience life without fatigue makes those days all the more poignant and joyful. 
Table 6 Results of DIF analyses of PNH versus general population

\begin{tabular}{|c|c|c|c|c|c|c|c|c|}
\hline \multirow[t]{3}{*}{ Item } & \multirow[t]{3}{*}{ Label } & \multirow[t]{3}{*}{ Domain } & \multicolumn{6}{|c|}{ DIF by Group (PNH vs. general population) } \\
\hline & & & \multicolumn{3}{|c|}{ Test of uniform DIF } & \multicolumn{3}{|c|}{ Test of non-uniform DIF } \\
\hline & & & $\begin{array}{l}\text { Likelihood } \\
\text { ratio test } p \\
\text { value }\end{array}$ & "Favored" group & $\begin{array}{l}\text { Odds ratio on } \\
\text { group effect }\end{array}$ & $\begin{array}{l}\text { Likelihood } \\
\text { ratio test } p \\
\text { value }\end{array}$ & $\begin{array}{l}\text { "Favored" group } \\
\text { at the mean total } \\
\text { domain score }\end{array}$ & $\begin{array}{l}\text { Odds ratio on } \\
\text { group effect at } \\
\text { the mean total } \\
\text { domain score }\end{array}$ \\
\hline eortc29 & $\begin{array}{l}\text { 29. How would you } \\
\text { rate your overall } \\
\text { health during the } \\
\text { past week? }\end{array}$ & Global & NS & NS & NS & NS & NS & NS \\
\hline eortc30 & $\begin{array}{l}\text { 30. How would you } \\
\text { rate your overall } \\
\text { quality of life dur- } \\
\text { ing the past week? }\end{array}$ & Global & NS & NS & NS & NS & NS & NS \\
\hline eortc01 & $\begin{array}{l}\text { 1. Do you have } \\
\text { any trouble doing } \\
\text { strenuous activities, } \\
\text { like carrying a } \\
\text { heavy shopping } \\
\text { bag or a suitcase? }\end{array}$ & Physical & $p<.001$ & General pop & 0.5326 & $p=.0214$ & General pop & 0.5599 \\
\hline eortc02 & $\begin{array}{l}\text { 2. Do you have any } \\
\text { trouble taking a } \\
\text { long walk? }\end{array}$ & Physical & $p<.001$ & Ecu/Ravu & 1.9937 & NS & NS & NS \\
\hline eortc03 & $\begin{array}{l}\text { 3. Do you have any } \\
\text { trouble taking a } \\
\text { short walk outside } \\
\text { of the house? }\end{array}$ & Physical & NS & NS & NS & NS & NS & NS \\
\hline eortc04 & $\begin{array}{l}\text { 4. Do you need } \\
\text { to stay in bed or } \\
\text { a chair during the } \\
\text { day? }\end{array}$ & Physical & NS & NS & NS & $p=.0089$ & Ecu/Ravu & 1.0833 \\
\hline eortc05 & $\begin{array}{l}\text { 5. Do you need } \\
\text { help with eating, } \\
\text { dressing, washing } \\
\text { yourself or using } \\
\text { the toilet? }\end{array}$ & Physical & NS & NS & NS & NS & NS & NS \\
\hline eortc06 & $\begin{array}{l}\text { 6. Were you limited } \\
\text { in doing either } \\
\text { your work or other } \\
\text { daily activities? }\end{array}$ & Role & NS & NS & NS & NS & NS & NS \\
\hline eortc07 & $\begin{array}{l}\text { 7. Were you limited } \\
\text { in pursuing your } \\
\text { hobbies or other } \\
\text { leisure time activi- } \\
\text { ties? }\end{array}$ & Role & NS & NS & NS & NS & NS & NS \\
\hline eortc21 & $\begin{array}{l}\text { 21. Did you feel } \\
\text { tense? }\end{array}$ & Emotional & $p<.001$ & General pop & 0.2567 & NS & NS & NS \\
\hline eortc22 & 22. Did you worry? & Emotional & NS & NS & NS & $p<.001$ & Ecu/Ravu & 1.3910 \\
\hline eortc23 & $\begin{array}{l}\text { 23. Did you feel } \\
\text { irritable? }\end{array}$ & Emotional & $p<.001$ & Ecu/Ravu & 2.8577 & NS & NS & NS \\
\hline eortc24 & $\begin{array}{l}\text { 24. Did you feel } \\
\text { depressed? }\end{array}$ & Emotional & $p<.001$ & General pop & 0.5886 & $p<.001$ & General pop & 0.7189 \\
\hline eortc20 & $\begin{array}{l}\text { 20. Have you } \\
\text { had difficulty in } \\
\text { concentrating on } \\
\text { things, like reading } \\
\text { a newspaper or } \\
\text { watching televi- } \\
\text { sion? }\end{array}$ & Cognitive & $p<.001$ & General pop & 0.2165 & $p<.001$ & General pop & 0.1177 \\
\hline eortc25 & $\begin{array}{l}\text { 25. Have you had } \\
\text { difficulty remem- } \\
\text { bering things? }\end{array}$ & Cognitive & $p<.001$ & Ecu/Ravu & 1.9155 & $p<.001$ & Ecu/Ravu & 1.6161 \\
\hline
\end{tabular}


Table 6 (continued)

\begin{tabular}{|c|c|c|c|c|c|c|c|c|}
\hline \multirow[t]{3}{*}{ Item } & \multirow[t]{3}{*}{ Label } & \multirow[t]{3}{*}{ Domain } & \multicolumn{6}{|c|}{ DIF by Group (PNH vs. general population) } \\
\hline & & & \multicolumn{3}{|c|}{ Test of uniform DIF } & \multicolumn{3}{|c|}{ Test of non-uniform DIF } \\
\hline & & & $\begin{array}{l}\text { Likelihood } \\
\text { ratio test } p \\
\text { value }\end{array}$ & "Favored" group & $\begin{array}{l}\text { Odds ratio on } \\
\text { group effect }\end{array}$ & $\begin{array}{l}\text { Likelihood } \\
\text { ratio test } p \\
\text { value }\end{array}$ & $\begin{array}{l}\text { "Favored" group } \\
\text { at the mean total } \\
\text { domain score }\end{array}$ & $\begin{array}{l}\text { Odds ratio on } \\
\text { group effect at } \\
\text { the mean total } \\
\text { domain score }\end{array}$ \\
\hline eortc26 & $\begin{array}{l}\text { 26. Has your physi- } \\
\text { cal condition or } \\
\text { medical treatment } \\
\text { interfered with } \\
\text { your family life? }\end{array}$ & Social & $p<.001$ & General pop & 0.3198 & $p=.0003$ & General pop & 0.5326 \\
\hline eortc27 & $\begin{array}{l}\text { 27. Has your physi- } \\
\text { cal condition or } \\
\text { medical treatment } \\
\text { interfered with } \\
\text { your social activi- } \\
\text { ties? }\end{array}$ & Social & $p<.001$ & General pop & 0.3135 & $p<.001$ & General pop & 0.1755 \\
\hline eortc10 & $\begin{array}{l}\text { 10. Did you need } \\
\text { to rest? }\end{array}$ & Fatigue & $p<.001$ & General pop & 0.3642 & NS & NS & NS \\
\hline eortc12 & $\begin{array}{l}\text { 12. Have you felt } \\
\text { weak? }\end{array}$ & Fatigue & NS & NS & NS & NS & NS & NS \\
\hline eortc18 & 18. Were you tired? & Fatigue & $p<.001$ & Ecu/Ravu & 2.4351 & $p<.001$ & Ecu/Ravu & 2.4843 \\
\hline eortc14 & $\begin{array}{l}\text { 14. Have you felt } \\
\text { nauseated? }\end{array}$ & Nauseau & $p=.0253$ & Ecu/Ravu & 1.8589 & $p<.001$ & General pop & 0.4916 \\
\hline eortc15 & $\begin{array}{l}\text { 15. Have you } \\
\text { vomited? }\end{array}$ & Nauseau & $p=.0006$ & General pop & 0.1791 & NS & NS & NS \\
\hline eortc09 & $\begin{array}{l}\text { 9. Have you had } \\
\text { pain? }\end{array}$ & Pain & $p<.001$ & General pop & 0.3012 & NS & NS & NS \\
\hline eortc19 & $\begin{array}{l}\text { 19. Did pain inter- } \\
\text { fere with your daily } \\
\text { activities? }\end{array}$ & Pain & NS & NS & NS & $p<.001$ & Ecu/Ravu & 1.4191 \\
\hline
\end{tabular}

*"Favored" = Finds it easier to endorse poor health except for eortc29 and eortc30

The present work had many strengths, including robust sample sizes and the use of a general-population comparison sample. Its limitations must, however, be acknowledged. First, the comparison group was very large at 15,000 , and so the multivariable analyses had sufficient power to detect very small effect sizes. This hypersensitivity is why we emphasize Cohen's $d$ effect sizes. Caution is also warranted in interpreting results because of the few items in each scale, especially when there are only two. Future research might replicate the responseshift analyses on groups of more similar size, or might investigate the longitudinal-DIF findings using measures of QOL cognitive appraisal [29] or interviews. Given the rarity of $\mathrm{PNH}$, this replication would be challenging.
Finally, in the multivariate analyses comparing people with $\mathrm{PNH}$ and the general population, we were ultimately able to adjust only for age, sex, and region. Other variables unexamined and unavailable in this study might be relevant to explaining or mediating these group differences, such as expectations.

In summary, people with $\mathrm{PNH}$ who were treated for 26 weeks with eculizumab or ravulizumab not only showed comparable effects on clinical outcomes, but also showed a notable and important QOL benefit-especially with ravulizumab. People with $\mathrm{PNH}$ also provided evidence of response shifts over time, suggesting that the treatments enabled adaptive changes. 
Table 7 Results of DIF analyses over time

\begin{tabular}{|c|c|c|c|c|c|c|}
\hline \multirow[t]{3}{*}{ Item } & \multirow[t]{3}{*}{ Label } & \multirow[t]{3}{*}{ Domain } & \multicolumn{4}{|c|}{ DIF over time within PNH patients } \\
\hline & & & \multicolumn{2}{|c|}{ Test of uniform DIF } & \multicolumn{2}{|c|}{ Test of non-uniform DIF } \\
\hline & & & $\begin{array}{l}p \text { value } \\
\text { (on group } \\
\text { effect) }\end{array}$ & "Favored" group & $\begin{array}{l}\text { Odds ratio on } \\
\text { group effect }{ }^{\varphi}\end{array}$ & $\begin{array}{l}p \text { value (on } \\
\text { interaction } \\
\text { term) }\end{array}$ \\
\hline eortc29 & $\begin{array}{l}\text { 29. How would you rate your overall } \\
\text { health during the past week? }\end{array}$ & Global & NS & NS & NS & NS \\
\hline eortc30 & $\begin{array}{l}\text { 30. How would you rate your overall } \\
\text { quality of life during the past week? }\end{array}$ & Global & NS & NS & NS & NS \\
\hline eortc01 & $\begin{array}{l}\text { 1. Do you have any trouble doing } \\
\text { strenuous activities, like carrying a } \\
\text { heavy shopping bag or a suitcase? }\end{array}$ & Physical & $p=.001$ & $\begin{array}{l}\text { As time increases, the likelihood of } \\
\text { endorsing decreases }\end{array}$ & 0.94 & NS \\
\hline eortc02 & $\begin{array}{l}\text { 2. Do you have any trouble taking a } \\
\text { long walk? }\end{array}$ & Physical & $p=.008$ & $\begin{array}{l}\text { As time increases, the likelihood of } \\
\text { endorsing decreases }\end{array}$ & 0.95 & NS \\
\hline eortc03 & $\begin{array}{l}\text { 3. Do you have any trouble taking a } \\
\text { short walk outside of the house? }\end{array}$ & Physical & NS & NS & NS & NS \\
\hline eortc04 & $\begin{array}{l}\text { 4. Do you need to stay in bed or a chair } \\
\text { during the day? }\end{array}$ & Physical & NS & NS & NS & NS \\
\hline eortc05 & $\begin{array}{l}\text { 5. Do you need help with eating, } \\
\text { dressing, washing yourself or using the } \\
\text { toilet? }\end{array}$ & Physical & NS & NS & NS & NS \\
\hline eortc06 & $\begin{array}{l}\text { 6. Were you limited in doing either your } \\
\text { work or other daily activities? }\end{array}$ & Role & $p<.001$ & $\begin{array}{l}\text { As time increases, the likelihood of } \\
\text { endorsing increases }\end{array}$ & 1.08 & NS \\
\hline eortc07 & $\begin{array}{l}\text { 7. Were you limited in pursuing your } \\
\text { hobbies or other leisure time activities? }\end{array}$ & Role & $p<.001$ & $\begin{array}{l}\text { As time increases, the likelihood of } \\
\text { endorsing decreases }\end{array}$ & 0.90 & NS \\
\hline eortc21 & 21. Did you feel tense? & Emotional & NS & NS & NS & NS \\
\hline eortc22 & 22. Did you worry? & Emotional & NS & NS & NS & NS \\
\hline eortc23 & 23. Did you feel irritable? & Emotional & $p=.009$ & $\begin{array}{l}\text { As time increases, the likelihood of } \\
\text { endorsing increases }\end{array}$ & 1.04 & $p=.031$ \\
\hline eortc24 & 24. Did you feel depressed? & Emotional & NS & NS & NS & NS \\
\hline eortc20 & $\begin{array}{l}\text { 20. Have you had difficulty in con- } \\
\text { centrating on things, like reading a } \\
\text { newspaper or watching television? }\end{array}$ & Cognitive & NS & NS & NS & NS \\
\hline eortc25 & $\begin{array}{l}\text { 25. Have you had difficulty remember- } \\
\text { ing things? }\end{array}$ & Cognitive & NS & NS & NS & NS \\
\hline eortc26 & $\begin{array}{l}\text { 26. Has your physical condition or } \\
\text { medical treatment interfered with your } \\
\text { family life? }\end{array}$ & Social & NS & NS & NS & NS \\
\hline eortc27 & $\begin{array}{l}\text { 27. Has your physical condition or } \\
\text { medical treatment interfered with your } \\
\text { social activities? }\end{array}$ & Social & NS & NS & NS & NS \\
\hline eortc10 & 10. Did you need to rest? & Fatigue & NS & NS & NS & NS \\
\hline eortc12 & 12. Have you felt weak? & Fatigue & $p<.001$ & $\begin{array}{l}\text { As time increases, the likelihood of } \\
\text { endorsing decreases }\end{array}$ & 0.93 & NS \\
\hline eortc18 & 18. Were you tired? & Fatigue & NS & NS & NS & $p=.003$ \\
\hline eortc14 & 14. Have you felt nauseated? & Nauseau & NS & NS & NS & NS \\
\hline eortc15 & 15. Have you vomited? & Nauseau & NS & NS & NS & NS \\
\hline eortc09 & 9. Have you had pain? & Pain & NS & NS & NS & $p=.002$ \\
\hline eortc19 & $\begin{array}{l}\text { 19. Did pain interfere with your daily } \\
\text { activities? }\end{array}$ & Pain & $p=.047$ & $\begin{array}{l}\text { As time increases, the likelihood of } \\
\text { endorsing decreases }\end{array}$ & 0.95 & NS \\
\hline
\end{tabular}

*"Favored" = Finds it easier to endorse poor health except for eortc29 and eortc30

${ }^{\varphi}$ Odds ratio converted to by-month estimate for ease of interpretation (i.e., daily estimate^${ }^{\wedge} 30$ ) 


\section{Abbreviations}

C5: Component-5; DIF: Differential item functioning; EORTC QLQ-C30: European Organisation for Research and Treatment of Cancer Quality of Life Questionnaire-C30; MANCOVA: Multivariate analysis of covariance; PNH: Paroxysmal nocturnal hemoglobinuria; PRO: Patient-reported outcome; QOL: Quality of life; SD: Standard deviation.

\section{Supplementary Information}

The online version contains supplementary material available at https://doi. org/10.1186/s13023-021-02016-8.

Additional file 1: Table S1. Baseline and treatment-naive PNH comparisons to general population (Cohen's d).

\section{Acknowledgements}

We are grateful for data management assistance from John Kaye, Jimmy Wang, and Ji Yu, and for helpful input from Dr. Francesca Martinelli, Dr. Austin G. Kulasekararaj, Dr. Anita Hill, Dr. Rodrigo Pavani, Dr. Sarah Guadagno, Ms. Asa Lommele, Mr. Simu Thomas, and Dr. Brian Healy. The authors thank the European Organization for Research and Treatment of Cancer for permission to use the data from EORTC study 0012015 for this research. The contents of this publication and methods used are solely the responsibility of the authors and do not necessarily represent the official views of the EORTC.

\section{Authors' contributions}

CES and RBS designed the research study. CES, RBS, and KB analyzed the data with relevant input from SN and KJM. CES wrote the paper and RBS, SN, KB, and KJM edited the manuscript. All authors read and approved the final manuscript.

\section{Funding}

This work was funded in part by Alexion Pharmaceuticals to Dr. Carolyn E. Schwartz at DeltaQuest Foundation.

\section{Availability of data and materials}

Alexion will consider requests for disclosure of clinical study participant-level data provided that participant privacy is assured through methods like data de-identification, pseudonymization, or anonymization (as required by applicable law), and if such disclosure was included in the relevant study informed consent form or similar documentation. Qualified academic investigators may request participant-level clinical data and supporting documents (statistical analysis plan and protocol) pertaining to Alexion-sponsored studies. Further details regarding data availability and instructions for requesting information are available in the Alexion Clinical Trials Disclosure and Transparency Policy at https://alexion.com/our-research/research-and-development. The EORTC norm data may be requested via https://www.eortc.org/data-sharing/.

\section{Declarations}

\section{Ethics approval and consent to participate}

The trial was approved by the institutional review board at each participating institution. All trial procedures performed in studies involving human participants were in accordance with the ethical standards of the institutional and/ or national research committee and with the 1964 Helsinki declaration and its later amendments or comparable ethical standards. All trial patients provided written informed consent for use of their data in primary and secondary analyses related to quality of life studies. For the EORTC general-population data, ethical approval was not sought as this study was solely based on panel research data collected by GfK SE. The survey conformed to the required ethical standards by obtaining written informed consent from all participants and collecting data completely anonymously.

\section{Consent for publication}

Not applicable.

\section{Competing interests}

Dr. Schwartz and Mr. Stark are employees of DeltaQuest Foundation, which received research funding for the work reported herein. Dr. Nolte declares no potential conflicts of interest and reports no disclosures. Mr. Myren is an employee of Alexion Pharmaceuticals which developed the drugs being evaluated.

\section{Author details}

${ }^{1}$ DeltaQuest Foundation, Inc., 31 Mitchell Road, Concord, MA 01742, USA. ${ }^{2}$ Departments of Medicine and Orthopaedic Surgery, Tufts University Medical School, Boston, MA, USA. ${ }^{3}$ Department of Measurement, Evaluation, Statistics, and Assessment, Boston College Lynch School of Education and Human Development, Chestnut Hill, MA, USA. ${ }^{4}$ Division of Psychosomatic Medicine, Medical Department, Charité - Universitätsmedizin Berlin, Corporate Member of Freie Universität Berlin and Humboldt-Universität Zu Berlin, Berlin, Germany. ${ }^{5}$ Health Economics and Outcome Research, Alexion Pharmaceuticals, Inc., Stockholm, Sweden

Received: 14 June 2021 Accepted: 24 August 2021 Published online: 15 September 2021

\section{References}

1. Alexion Pharmaceuticals. Module 2: description of disease. In: Global value dossier for pricing and reimbursement submissions; 2020.

2. Hillmen P, Lewis S, Bessler M, Luzzatto L, Dacie JV. Natural history of paroxysmal nocturnal hemoglobinuria. N Engl J Med. 1995;333(19):1253-8.

3. Nishimura J-I, Kanakura Y, Ware RE, et al. Clinical course and flow cytometric analysis of paroxysmal nocturnal hemoglobinuria in the United States and Japan. Medicine. 2004;83(3):193-207.

4. Hill A, Rother RP, Wang X, et al. Effect of eculizumab on haemolysisassociated nitric oxide depletion, dyspnoea, and measures of pulmonary hypertension in patients with paroxysmal nocturnal haemoglobinuria. $\mathrm{Br}$ J Haematol. 2010;149(3):414-25.

5. Hillmen $\mathrm{P}$, Elebute $\mathrm{M}$, Kelly $\mathrm{R}$, et al. Long-term effect of the complement inhibitor eculizumab on kidney function in patients with paroxysmal nocturnal hemoglobinuria. Am J Hematol. 2010;85(8):553-9.

6. Parker C, Omine M, Richards S, et al. Diagnosis and management of paroxysmal nocturnal hemoglobinuria. Blood. 2005;106(12):3699-709.

7. Weitz I, Meyers G, Lamy T, et al. Cross-sectional validation study of patient-reported outcomes in patients with paroxysmal nocturnal haemoglobinuria. Intern Med J. 2013;43(3):298-307.

8. Schrezenmeier $H$, Muus P, Socié $G$, et al. Baseline characteristics and disease burden in patients in the international paroxysmal nocturnal hemoglobinuria registry. Haematologica. 2014;99(5):922.

9. Hillmen P, Muus P, Röth A, et al. Long-term safety and efficacy of sustained eculizumab treatment in patients with paroxysmal nocturnal haemoglobinuria. Br J Haematol. 2013;162(1):62-73.

10. Loschi M, Porcher R, Barraco F, et al. Impact of eculizumab treatment on paroxysmal nocturnal hemoglobinuria: a treatment versus no-treatment study. Am J Hematol. 2016;91(4):366-70.

11. Socié G, Mary J-Y, de Gramont A, et al. Paroxysmal nocturnal haemoglobinuria: long-term follow-up and prognostic factors. Lancet. 1996;348(9027):573-7.

12. Kelly RJ, Hill A, Arnold LM, et al. Long-term treatment with eculizumab in paroxysmal nocturnal hemoglobinuria: sustained efficacy and improved survival. Blood. 2011;117(25):6786-92.

13. Yenerel MN, Muus P, Wilson A, Szer J. Clinical course and disease burden in patients with paroxysmal nocturnal hemoglobinuria by hemolytic status. Blood Cells Mol Dis. 2017;65:29-34.

14. Lee JW, Jang JH, Kim JS, et al. Clinical signs and symptoms associated with increased risk for thrombosis in patients with paroxysmal nocturnal hemoglobinuria from a Korean Registry. Int J Hematol. 2013;97(6):749-57.

15. Yu F, Du Y, Han B. A comparative analysis of clinical characteristics of patients with paroxysmal nocturnal hemoglobinuria between Asia and Europe/America. Int J Hematol. 2016;103(6):649-54.

16. Schrezenmeier $H$, Röth A, Araten DJ, et al. Baseline clinical characteristics and disease burden in patients with paroxysmal nocturnal hemoglobinuria (PNH): updated analysis from the International PNH Registry. Ann Hematol. 2020:99(7):1505-14.

17. Jalbert JJ, Chaudhari U, Zhang H, Weyne J, Shammo JM. Epidemiology of PNH and real-world treatment patterns following an incident PNH diagnosis in the US. Blood. 2019;134:3407. 
18. Socié G, Schrezenmeier H, Muus P, et al. Changing prognosis in paroxysmal nocturnal haemoglobinuria disease subcategories: an analysis of the International PNH Registry. Intern Med J. 2016;46(9):1044-53.

19. Ueda $Y$, Obara $N$, Yonemura $Y$, et al. Effects of eculizumab treatment on quality of life in patients with paroxysmal nocturnal hemoglobinuria in Japan. Int J Hematol. 2018;107(6):656-65.

20. Jang JH, Kim JS, Yoon S-S, et al. Predictive factors of mortality in population of patients with paroxysmal nocturnal hemoglobinuria $(\mathrm{PNH})$ : results from a Korean PNH registry. J Korean Med Sci. 2016:31(2):214

21. Kulasekararaj AG, Hill A, Rottinghaus ST, et al. Ravulizumab (ALXN1210) vs eculizumab in C5-inhibitor-experienced adult patients with $\mathrm{PNH}$ : the 302 study. Blood. 2019;133(6):540-9.

22. Lee JW, Sicre de Fontbrune F, Wong Lee Lee L, et al. Ravulizumab (ALXN1210) vs eculizumab in adult patients with PNH naive to complement inhibitors: the 301 study. Blood. 2019;133(6):530-9.

23. Niedeggen $C$, Singer $S$, Groth $M$, et al. Design and development of a disease-specific quality of life tool for patients with aplastic anaemia and/ or paroxysmal nocturnal haemoglobinuria (QLQ-AA/PNH) - a report on phase III. Ann Hematol. 2019;98(7):1547-59.

24. Ahmed S, Mayo NE, Corbiere M, Wood-Dauphinee S, Hanley J, Cohen R. Change in quality of life in people with stroke over time: True change or response shift? Qual Life Res. 2005;14:611-27.

25. Bernhard J, Hurny C, Maibach R, Herrmann R, Laffer U. Quality of life as subjective experience: reframing of perception in patients with colon cancer undergoing radical resection with or without adjuvant chemotherapy. Swiss Group for Clinical Cancer Research (SAKK). Ann Oncol. 1999;10(7):775-82.

26. Bernhard J, Lowy A, Mathys N, Herrmann R, Hürny C. Health related quality of life: A changing construct? Qual Life Res. 2004;13(7):1187-94.

27. Bochner B, Schwartz CE, Garcia I, Goldstein L, Zhang J, Rapkin BD. Understanding the impact of radical cystectomy and urinary diversion in patients with bladder cancer: treatment outcomes clarified by appraisal process. Qual Life Res. 2017;26(Suppl 1):6-7.

28. Boucekine M, Loundou A, Baumstarck K, et al. Using the random forest method to detect a response shift in the quality of life of multiple sclerosis patients: a cohort study. BMC Med Res Methodol. 2013;13:20.

29. Breetvelt IS, Van Dam FS. Underreporting by cancer patients: the case of response-shift. Soc Sci Med. 1991;32(9):981-7.

30. Cella D, Hahn EA, Dineen K. Meaningful change in cancer-specific quality of life scores: differences between improvement and worsening. Qual Life Res. 2002;11(3):207-21.

31. Chapman GB, Elstein AS, Kuzel TM, et al. Prostate cancer patients' utilities for health states: how it looks depends on where you stand. Med Decis Mak. 1998;18(3):278-86.

32. Fayers PM, Langston AL, Robertson C, PRISM Trial Group. Implicit selfcomparisons against others could bias quality of life assessments. J Clin Epidemiol. 2007;60(10):1034-9.

33. Finkelstein JA, Stark RB, Lee J, Schwartz CE. Patient factors that matter in predicting spine surgery outcomes: a machine learning approach. J Neurosurg Spine. 2021;1(aop):1-10.

34. King-Kallimanis BL, Oort FJ, Nolte S, Schwartz CE, Sprangers MAG Using structural equation modeling to detect response shift in disability and QOL scores of multiple sclerosis patients. Qual Life Res. 2011;20(10):1527-40.

35. Li Y, Rapkin BD. Classification and regression tree analysis to identify complex cognitive paths underlying quality of life response shifts: a study of individuals living with HIV/AIDS. J Clin Epidemiol. 2009;62:1138-47.

36. McPhail S, Haines T. Response shift, recall bias and their effect on measuring change in health-related quality of life amongst older hospital patients. Health Qual Life Outcomes. 2010;8(1):1.

37. Oort FJ, Visser MRM, Sprangers MAG. An application of structural equation modeling to detect response shifts and true change in quality of life data from cancer patients undergoing invasive surgery. Qual Life Res. 2005;14:599-609.

38. Osbourne $\mathrm{RH}$, Hawkins M, Sprangers MA. Change of perspective: A measurable and desired outcome of chronic disease self-management intervention programs that violates the premise of preintervention/ postintervention assessment. Arthritis Rheum. 2006:55(3):458-65.

39. Razmjou $H$, Yee A, Ford M, Finkelstein JA. Response shift in outcome assessment in patients undergoing total knee arthroplasty. J Bone Joint Surg. 2006;88(12):2590-5
40. Sajobi TT, Fiest KM, Wiebe S. Changes in quality of life after epilepsy surgery: the role of reprioritization response shift. Epilepsia. 2014;55(9):1331-8

41. Schwartz CE, Sajobi T, Lix L, Quaranto BR, Finkelstein JA. Changing values, changing outcomes: the influence of reprioritization response shift on outcome assessment after spine surgery. Qual Life Res. 2013;22(9):2255-64.

42. Schwartz CE, Sprangers MAG, Carey A, Reed G. Exploring response shift in longitudinal data. Psychol Health. 2004;19(1):51-69.

43. Sprangers MAG, Schwartz CE. Integrating response shift into healthrelated quality of life research: a theoretical model. Soc Sci Med. 1999:48(11):1507-15.

44. Schwartz CE, Sprangers MAG. Methodological approaches for assessing response shift in longitudinal health-related quality-of-life research. Soc Sci Med. 1999;48(11):1531-48

45. Rapkin BD. Personal goals and response shifts: understanding the impact of illness and events on the quality of life of people living with AIDS 8400 In: Schwartz CE, Sprangers MAG, editors. Adaptation to changing health: response shift in quality-of-life research. Washington: American Psychological Association; 2000. p. 53-71.

46. Rapkin BD, Schwartz CE. Advancing quality-of-life research by deepening our understanding of response shift: a unifying theory of appraisal. Qual Life Res. 2019;28(10):2623-30.

47. Schwartz CE, Bode R, Repucci N, Becker J, Sprangers MAG, Fayers PM. The clinical significance of adaptation to changing health: a meta-analysis of response shift. Qual Life Res. 2006;15:1533-50.

48. Razmjou H, Schwartz CE, Holtby R. Response shift had an independent impact on perceived disability two years following rotator cuff surgery. J Bone Joint Surg. 2010;92:2178-86.

49. Rapkin BD, Schwartz CE. Toward a theoretical model of quality-of-life appraisal: Implications of findings from studies of response shift. Health Qual Life Outcomes. 2004;2(1):14.

50. Schwartz CE, Andresen E, Nosek M, Krahn G, RRTC Expert Panel on Health Status Measurement. Response shift theory: important implications for measuring quality of life in individuals with disability. Arch Phys Med Rehabil. 2007:88:529-36.

51. Schwartz CE, Stucky BD, Rivers CS, Noonan VK, Finkelstein JA. Quality of life and adaptation in people with spinal cord injury: response shift effects five-years post-injury. Arch Phys Med Rehabil. 2018;99:1599-608.

52. Holland PW, Wainer H. Differential item functioning. Hillsdale: Erlbaum; 1993.

53. Nolte $\mathrm{S}$, Liegl G, Petersen M, et al. General population normative data for the EORTC QLQ-C30 health-related quality of life questionnaire based on 15,386 persons across 13 European countries, Canada and the Unites States. Eur J Cancer. 2019;107:153-63.

54. Fayers P, Bottomley A, Group EQoL. Quality of life research within the EORTC - the EORTC QLQ-C30. Eur J Cancer. 2002;38:125-33.

55. Aaronson NK, Ahmedzai S, Bergman B, et al. The European organization for research and treatment of cancer QLQ-C30: a quality-of-life instrument for use in international clinical trials in oncology. J Natl Cancer Inst. 1993:85(5):365-76.

56. Liegl G, Petersen M, Groenvold M, et al. Establishing the European Norm for the health-related quality of life domains of the computer-adaptive test EORTC CAT Core. Eur J Cancer. 2019;107:133-41.

57. Cohen J. A power primer. Psychol Bull. 1992;112:155-9.

58. Zumbo BD. A handbook on the theory and methods of differential item functioning (DIF): logistic regression modeling as a unitary framework for binary and likert-type (ordinal) item scores. Ottawa: Directorate of Human Resources Research and Evaluation, Department of National Defense; 1999.

59. Swaminathan $H$, Rogers $H J$. Detecting differential item functioning using logistic regression procedures. J Educ Meas. 1990;27(4):361-70.

60. IBM SPSS Statistics for Windows [computer program]. Version 27. Armonk, NY: IBM Corp; 2020

61. Stata Statistical Software: Release 16.1 [computer program]. College Station, TX: StataCorp LLC: 2019.

\section{Publisher's Note}

Springer Nature remains neutral with regard to jurisdictional claims in published maps and institutional affiliations. 